\title{
Prophylactic Approach to Industrial Electro- Traumatism Taking into Account Individual Psycho-Physical Peculiarities of Worker Taking into Account Network Digitalization
}

\author{
Dmitriy Kuvshinov ${ }^{1}$, Sergey Zakharenko², Sergey Zakharov², Yana Yakunina ${ }^{1}$, and \\ Vyacheslav Voronin ${ }^{2}$ \\ ${ }^{1}$ Kemerovo State Medical University, 650056, 22a Voroshilova St., Kemerovo, Russia \\ ${ }^{2}$ T.F. Gorbachev Kuzbass State Technical University, 650000, 28 Vesennyaya St., Kemerovo, Russia
}

\begin{abstract}
The article assesses electrical safety in electrical installations, considers the risks and factors affecting a working person. Electrical injury, compared with other types of industrial injuries, is a relatively small percentage, however, the number of injuries with severe and fatal outcomes occupies a leading place. That is why electrical safety issues need to be given the closest attention. To ensure safe working conditions during the operation of electrical installations, it is necessary to know how electric current acts on the human body, conditions of exposure to hazardous voltage, protection measures against electric shock. The topic of the article is of great practical importance both for those interested in electrical safety issues and for employees and enterprises of the energy industry.
\end{abstract}

\section{Introduction}

Preserving the life and health of employees of an organization is a priority vector direction of state policy in the field of labor protection and in the activities of all employees. Other business interests go to the second plan. This dictates the need to conduct systematic work in the field of labor safety in all organizations aimed at reducing the risk of injuries and occupational diseases. Therefore, the study of the causes and the development of appropriate measures to reduce injuries is a very urgent task.

Specific occupational risks inherent only in the electric power industry, the most serious of which is the danger of electric shock, make it necessary for employers to build a strict policy of strict observance of all types of labor protection requirements, production and labor discipline by all employees.

Over the past ten years, Russia has maintained a positive trend to reduce occupational injuries in all types of enterprises in all sectors. The Rostrud data show the dynamics of fatal injuries both in the whole of the Russian Federation and in the form of economic activity "Production and Distribution of Electricity, Gas and Water". Statistics are shown in Figure 1. 


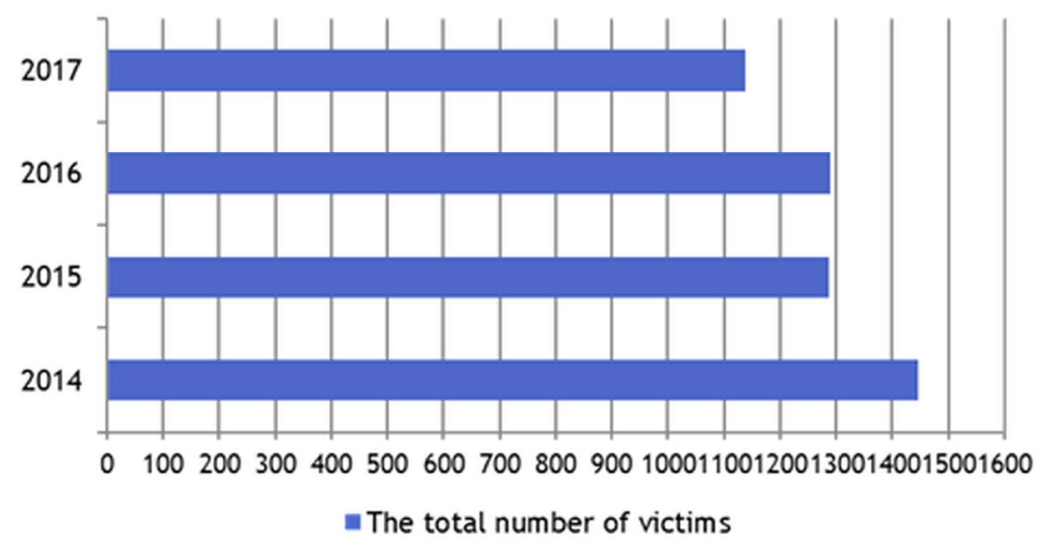

Fig. 1. Number of fatal industrial injuries (including women) in 2014-2017 (according to Rostrud).

\section{Results and discussion}

Consider the distribution of accidents by type of facility. 3.6\% of fatal accidents occurred in heat generating plants and heating networks, $35.7 \%$ in consumers electrical installations, $3.6 \%$ in thermal power plants, and $57.1 \%$ in electric networks. The information is presented in the form of a diagram, Figure 2.

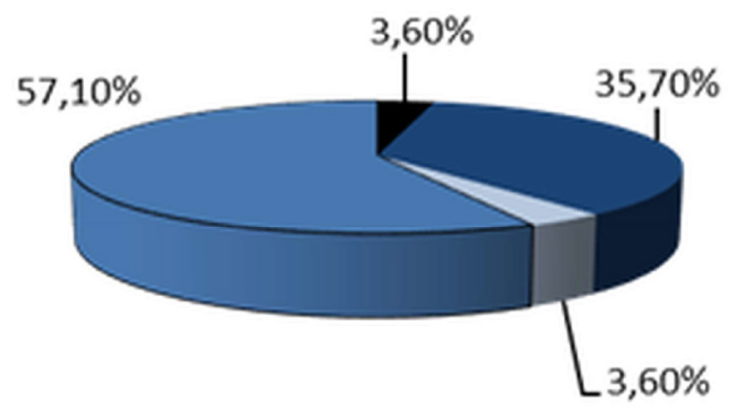

- Heat generating plants and heat networks

Consumer electrical installations

Thermal power plants

\section{Electric networks}

Fig. 2. The distribution of accidents by types of objects.

According to official statistics for the Russian Federation as a whole and for the type of activity "Production and Distribution of Electricity", there is a tendency towards a decrease in the total number of victims of accidents in any field of production and the number of fatal injuries. Thus, the work to eliminate the circumstances and causes of injuries (including fatal), carried out by employers, gives positive results and the hope of approaching the standards of safe work in the workplace.

The main traumatic factor in any energy enterprise is electric shock.

The causes of accidents that occurred in 2017 are shown in Figure 3.

Analysis of industrial accidents that occurred in 2017 in organizations of the Russian Federation showed that the main causes of accidents were: the fall of the injured person (victim) from a height (12\% of the total number of accidents); in $14 \%$ of cases, death was 
the result of exposure to rotating, scattering, moving objects, parts, machines and mechanisms; $74 \%$ of electric shocks.

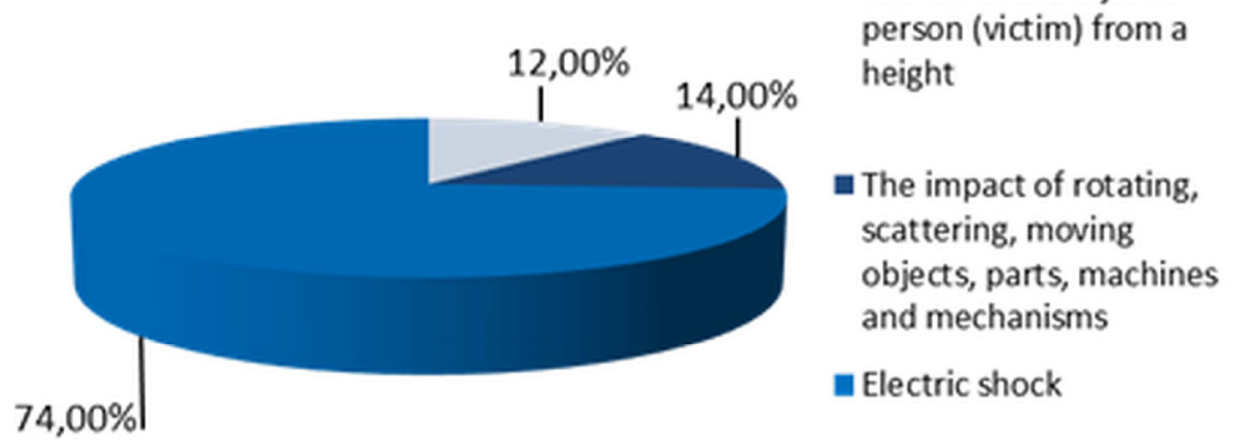

Fig. 3. Causes of fatal accidents in 2017.

The frequency of injuries from electric shocks in developed countries is 2-3 cases per 100,000 population [4]. Annually, as a result of exposure to electric current, 22-25 thousand people die in the world, and among the fatal outcomes in production, electric trauma takes the fifth place [6].

The analysis showed that the total number of accidents at electric power enterprises in 2017 decreased compared to 2016, but continues to remain high.

The main factors of the causes of accidents are:

- failure to perform technical and organizational measures in preparation for work;

- expansion of the workplace and the volume of the task;

- intentional violation of safety rules during the performance of work;

- lack of sufficient qualifications and experience of the staff.

The listed reasons indicate that accidents with personnel occur due to a lack of basic knowledge, inadequate qualifications and training of personnel. This is especially true for remote areas of energy enterprises, where the selection of qualified personnel for electrical engineering positions is difficult. It was established that the younger the employee, the higher the frequency of electrical injuries, which is due to the low level of qualification of personnel [14].

However, the probability of electrical injuries for personnel with extensive experience and a high level of qualification is also high. This is due to the fact that they have to carry out the bulk of the work and, therefore, the probability of getting under voltage is higher than that of workers with little experience. A high level of electrical injuries is also observed if work is carried out overtime, due to psychophysiological factors (inattention, fatigue, etc.).

Assessment of risks, dangers and their definition is an important task in the fight against electrical injuries. These skills allow you to learn how to manage these risks and form the skills of the staff to identify the main production risks.

Risk is a combination of the probabilities of a hazardous event or exposure and the severity of the injury or ill health that could be caused by such an event or exposure.

When assessing possible risks, it is necessary to proceed from the severity of the consequences and measures to manage them. Management activities should be proportionate to risk.

Should be considered: 
- what risks can be eliminated?

- what risks can be managed?

- what effective measures can be taken?

Key risk management measures:

- compliance with instructions and rules in full;

- use of PPE;

- observance of labor discipline;

- self-and mutual control.

Key principles in identifying and eliminating risk:

- perform a risk assessment;

- develop and take measures to eliminate the risk;

- if it is impossible to eliminate the risk, it is necessary to take measures to individual or collective protection.

Consider approaches to identifying risks at the stage of task formation and until the moment of the accident itself.

According to statistics, the frequency of occurrence of situations that led to injury obeys the laws in the form of a pyramid, which is based on the risks that occur in the workplace. At the heart of one death are from a thousand to several tens of thousands of dangerous conditions. This principle is described in the theory of F. Bird, which clearly shows the statistics of the distribution of accidents (Figure 4). As can be seen from the figure, a minor violation, which is not given an appropriate assessment, develops into injuries of varying severity. This theory shows the way to manage industrial safety. To change the quantitative indicators located at the top, it is necessary to change the base of the pyramid.

From the foregoing, we can conclude that one of the principles of ensuring labor safety is the fight against sources of risk.

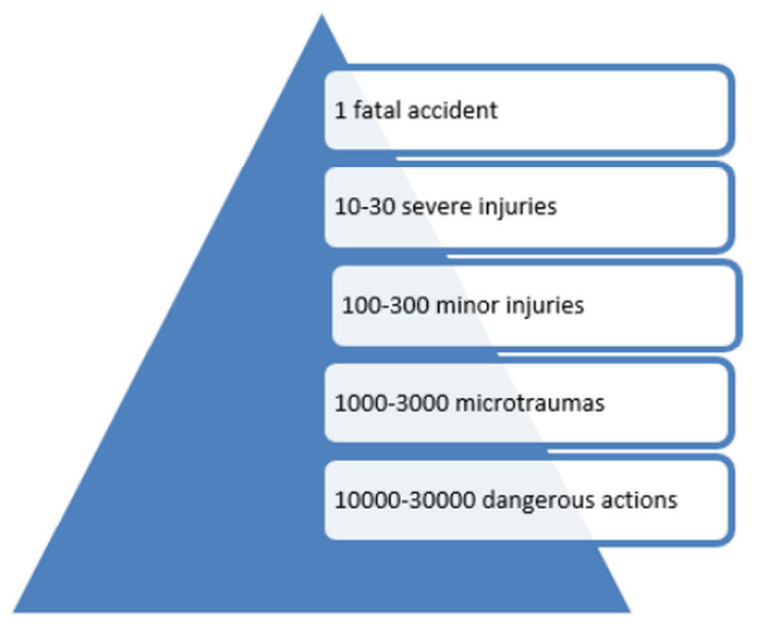

Fig. 4. Byrd Pyramid.

In addition, there is a Bradley curve - an effective tool in improving occupational safety. According to this pattern - the more joint efforts are made to ensure electrical safety, the less the likelihood of accidents. Employees must ensure the safe execution of work not only under the influence of instincts and management supervision, but also actively acting, both personally and in a team.

Over the long history of the development of the electric power industry, a whole system of labor protection management has been created. It provides an opportunity to apply an 
integrated approach to security issues, however, the achieved level can still not be considered satisfactory.

In general, the problem of "man and technology" is one of the main problems of modern science. Its solution involves collaboration: physiologists, mathematicians, psychologists, engineers, anatomists and representatives of many other scientific disciplines, because this problem requires an integrated approach to solving it.

There is a need to develop a different fundamental approach to the analysis of systems "man - electrical installation." The task of researching a person as an operator (and only as an operator) turns into the task of researching an operator as a person [9].

Imagine the factors affecting a working person in the form of Figure 5.

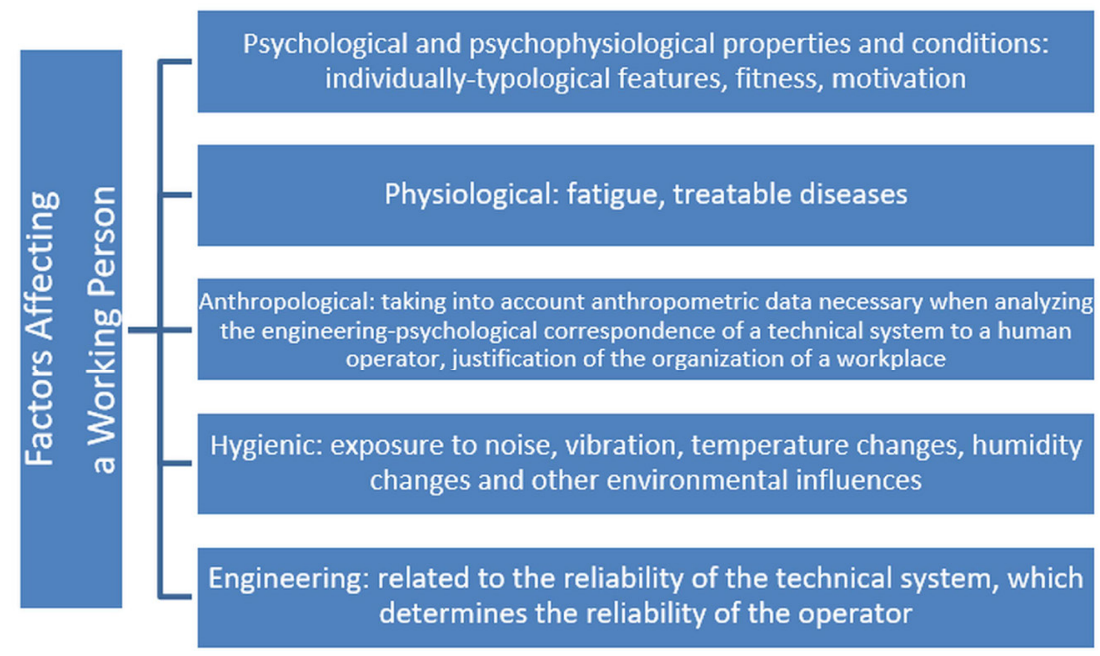

Fig. 5. Factors affecting a working person.

When selecting for work in such enterprises where work is based on the "man-machine" system, and especially if work is associated with responsibility and a threat to life, one should carefully consider the mental state of a person. For example, to assess his temperament and character, a particularly important role is played by the properties of temperament in activities related to the extreme conditions of time pressure and life threatening. Character anomalies associated with disturbances in the emotional-volitional sphere are called "psychopathies." Usually, four types of them are distinguished (Figure 6).

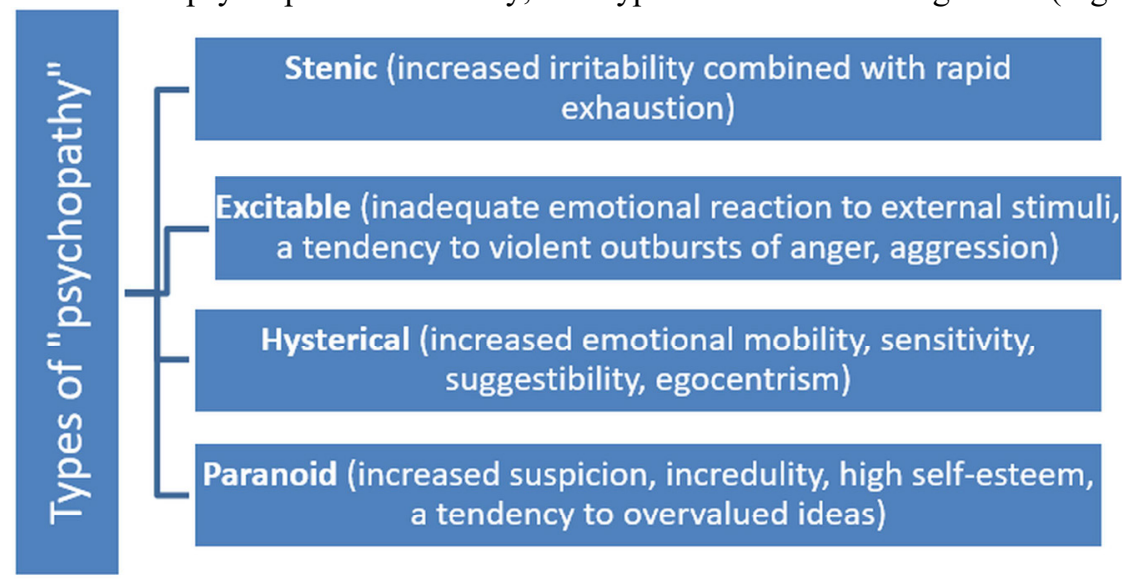


Fig.6. Types of «psychopathy».

It is necessary to exclude the possibility of admission of persons with psychopathic and psychopathological traits. This is implemented in psychological testing procedures.

For example, when selecting for work, the type of higher nervous activity should be taken into account, since people with different types of higher nervous activity react differently to various stimuli. In choleric patients, nervous processes are characterized by a predominance of excitement over inhibition. It is difficult for such an employee to control his actions. Consequently, the risk of industrial electrical injuries increases.

A significant risk factor is stress. The state of mental stress that occurs in a person under the most difficult conditions in the process of carrying out his activities not only in everyday life, but also in extreme conditions can provoke electrical injury. Under stress, the electrical resistance of the skin changes. It can range from 2,000 ohms to 2,000,000 ohms.

Skin resistance:

- faces and rear of the brush is in the range from 10,000 to $20,000 \mathrm{ohms}$,

- hips - 2,000,000 ohms,

- palms and soles - from 200,000 ohms to 2,000,000 ohms.

For comparison, internal organs and tissues have a resistance of only about 500-1000 ohms. The resistance of the human body, depending on the state of the body and environmental conditions, fluctuates over a very wide range and therefore is of great importance for the outcome of electrical injury. Especially with voltages up to $500 \mathrm{~V}$ (at high voltages, resistance is of less importance).

The condition of the skin can significantly affect the nature of the electric trauma, as follows - what was the skin at the time of the injury, for example, if it is thick, dry, then the skin has a lot of resistance. Of great importance is the moisture of the skin. The resistance of the skin moistened with water drops by $40 \%$. This explains the increased risk of electrical injury in the hot season and in "hot", humid rooms.

The amount of sweat glands in the skin, the degree of its blood supply, and contamination with various substances are also important. The condition of the skin also depends on the state of the organism as a whole - its reactivity, the state of the nervous, endocrine and other systems. Therefore, skin resistance is not the same in different people, in different parts of the body of one person and in one area at different times [2].

According to a number of studies, up to $20.3 \%$ of electricians experience stress at the workplace, especially people working on power grids with a high voltage class [11].

Stress at work is a reaction to the presentation of requirements to employees that do not correspond to the level of their knowledge and skills, as well as the need to act in conditions of lack of time or lack of information. Occupational stress is a diverse phenomenon, expressed in reactions (mental and physical) to stressful situations of work. Stress is present even in well-managed organizations, which depends not only on structural and organizational characteristics and the nature of work, but also on interpersonal relationships of employees. All employees are subject to stress, regardless of workload, and in turn, stress leads to a decrease in a person's working capacity.

Both organizations and individuals are very concerned about stress and its consequences. Attempts to manage stress can be represented in the form of Figure 7, which involves the selection of one of the possible solutions. 


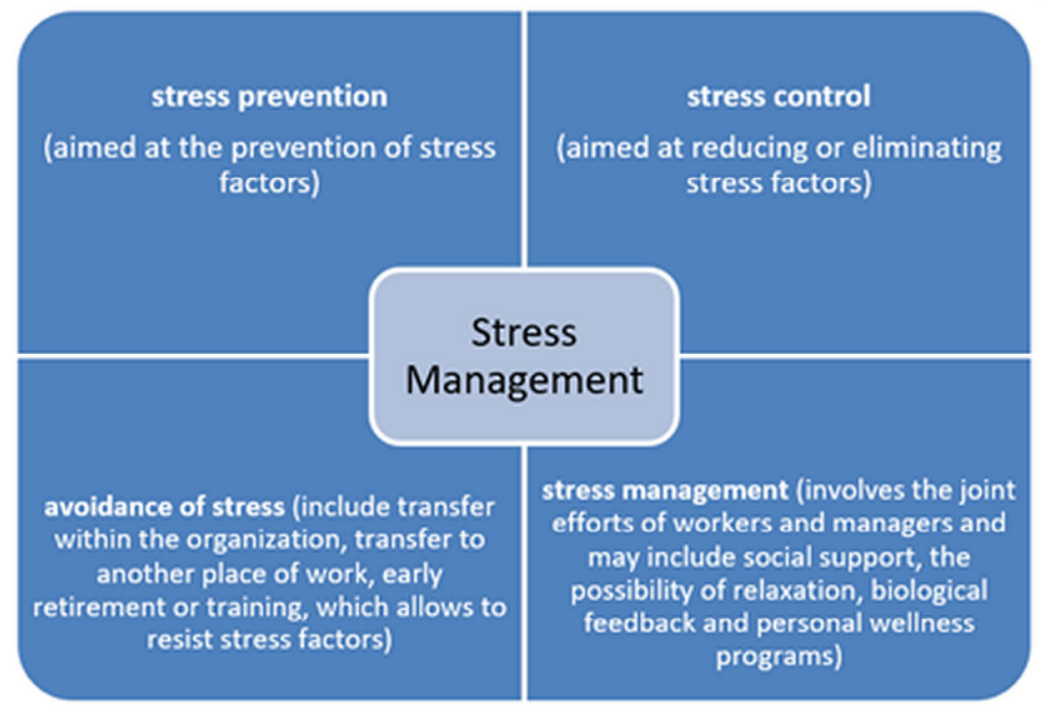

Fig. 7. Stress Management.

Thus, the data presented provide clearer guidelines for planning and developing corrective programs in the direction of occupational safety psychology, thereby increasing the effectiveness of safety measures. The experience of psychologists shows that a positive effect is achieved by recognizing the insufficiency of professionally important qualities individually for each employee and the phased formation of adaptive ways of their development.

One of the important directions of increasing the effectiveness of security is the digitalization of the network, which cannot be successful without the implementation of the concept of "Digital Electrician". "Digital electrician" is a concept of organizational and hardware-software complex, designed to increase the safety of work at electric grid facilities and automate the processes of their planning, execution and control.

Increasing the effectiveness of organizations' activity in the use of digital resources is reflected, for example, in the strategy for the development of the information society in Russia for the period 2017-2030, which focuses on the massive introduction of digital interaction tools of complex systems, in particular, integrated production structures. Currently, the project "Digital Electrician" is being implemented in the electric power industry. The project aims to solve problems associated with the violation of labor protection rules during work on operating electrical installations.

The project "Digital Electrician" implies control, which is ensured by:

- monitoring a labor protection worker on a daily basis;

- visualization - the psychological preparation of the employee to comply with labor protection requirements.

Monitoring of a labor protection worker on a daily basis can be presented in the form of a diagram (Figure 8). The electrician turns on the smartphone, then enters the password (you can use the personnel number), is tested where he needs to answer 3 questions with 3 possible answers. If the answer is given correctly - the work permit is received, if the wrong answer is given, then the work permit is received, but the next day an additional question is raised on the topic in which the mistake was made. At the end of the month, the immediate supervisor analyzes the test results in order to identify poor employee knowledge, on the basis of which a technical training plan is formed. 


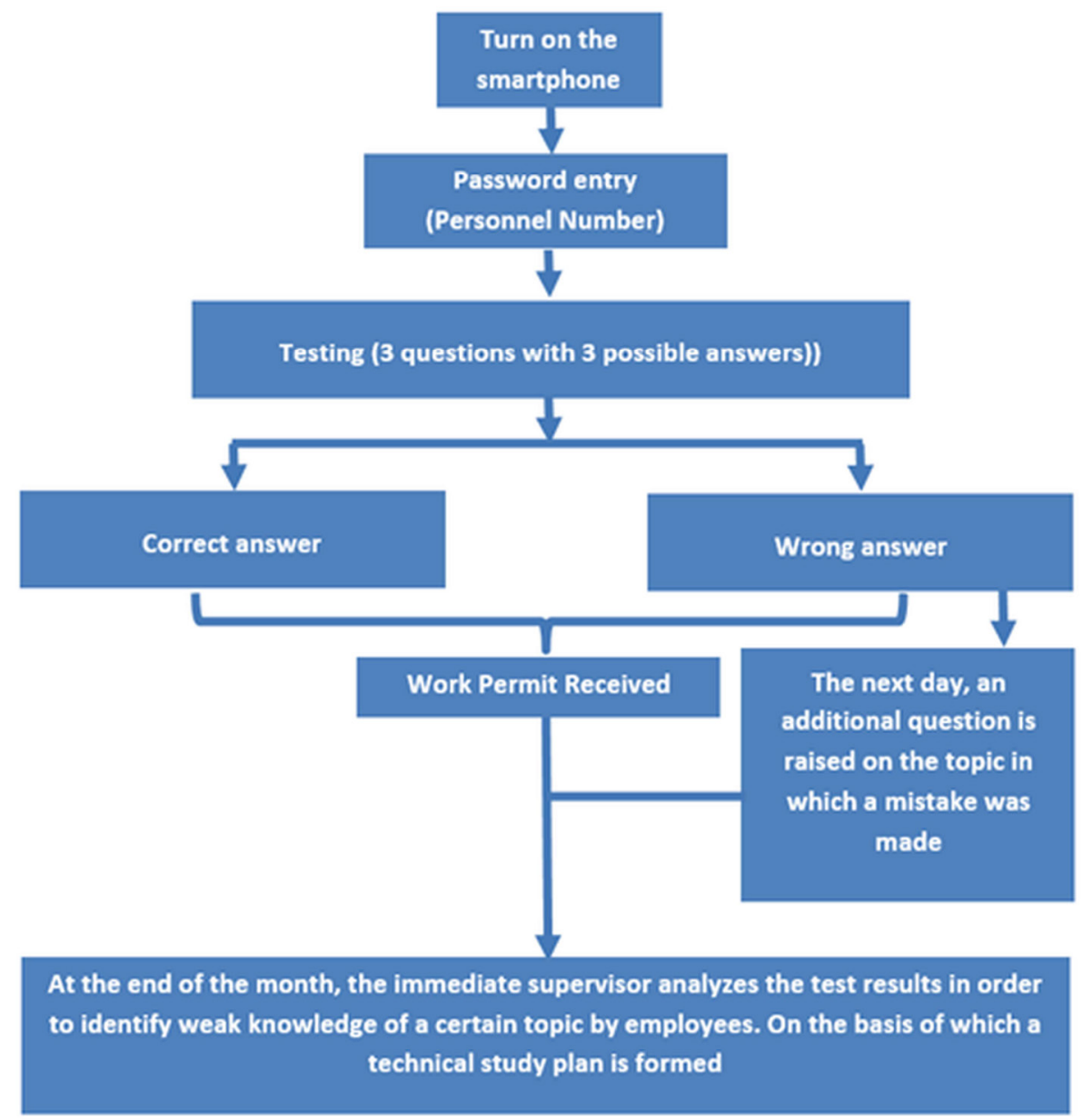

Fig. 8. Daily labor protection monitoring.

Visualization - the psychological preparation of the employee to comply with labor protection requirements consists in the fact that prior to arrival at the place of work, assigning order - allowance, admissions worker, the work producer, brigade members, slinger, monkey board worker, manipulator crane operator, provides visual and psychological training, in part security measures when performing future work specified in the order - allowance. For clarity of this principle, let us imagine the work on the tolerance: "Replacing a wooden support with a reinforced concrete support" in the form of a diagram of Figure 9. From Figure 9 it is seen that for each category of workers, training is carried out, depending on the type of work they perform, and thereby actually prepares them for immediate implementation. 


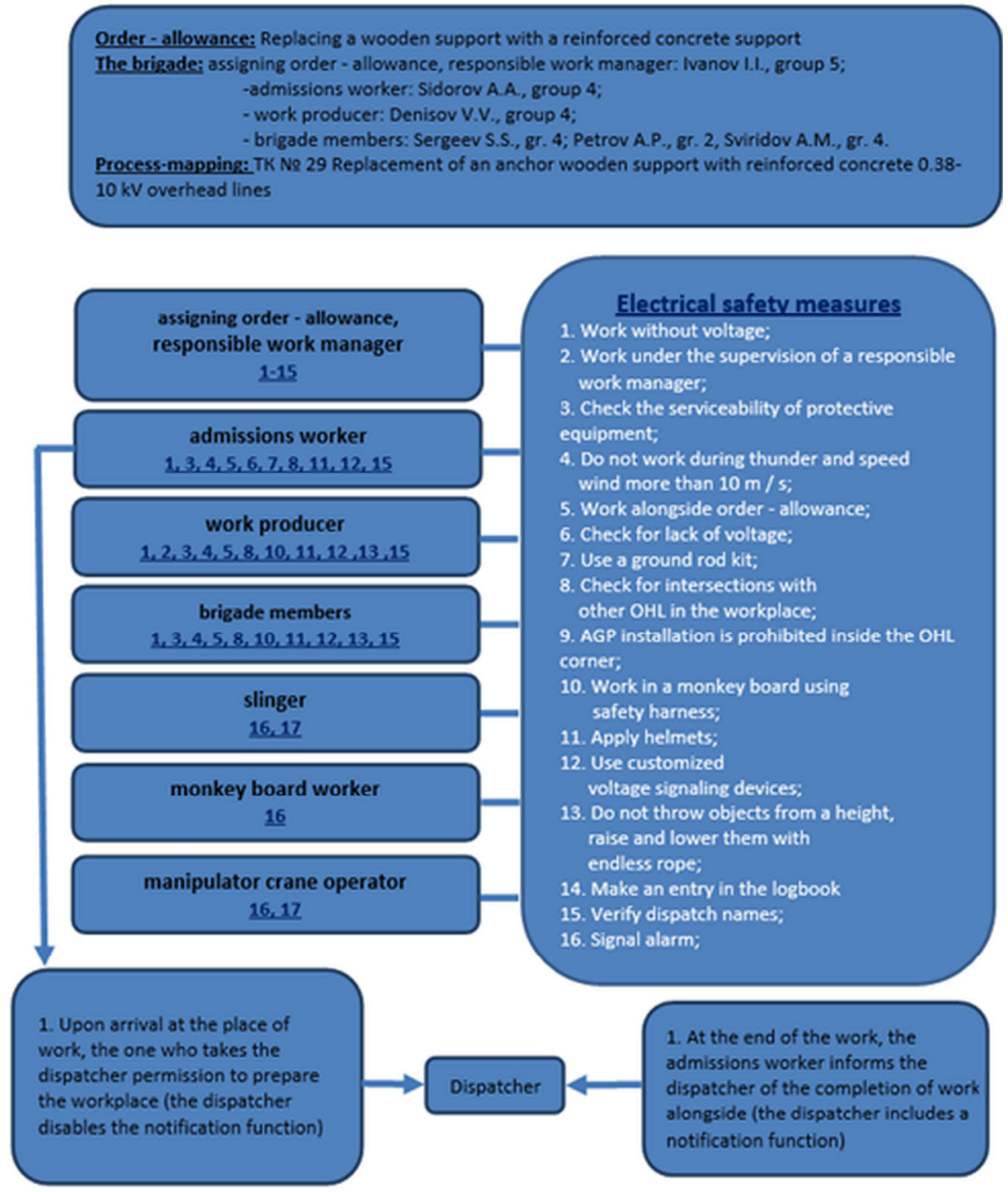

Fig. 9. Visualization - psychological training of the employee to comply with labor protection requirements.

The «Digital Electrician» project will require staff to master new knowledge and communication skills with high-tech production tools, computer technologies. The formation of such competencies and skills will accelerate the adaptation to new knowledge, which is relevant in the context of dynamically changing technologies in the electric power industry. Ultimately, a conscious perception of the concept of "Digital Electrician" reduces the desynchronization of the mental and emotional processes of the electrician's body, increases its adaptive potential, and also helps to identify employees at risk.

The individual component of the adaptive potential is assessed by measuring indicators characterizing the stability of various body systems to adaptive loads and the rate of return of the measured parameters to some optimal values, highlighting the patterns of organization and the course of the systemic adaptive reaction at the organism level, and the formation of adaptive neoplasms [4]. The individual characteristics of the adaptive potential, reflecting the functional state of the body, are one of the significant components of the «Digital Electrician» project. 
In terms of the impact of the «Digital Electrician» on psychophysiological indicators, the following should be noted. The ability to independently carry out control of local and summary tasks under conditions of time limits and performers, control of communications, the use of essentially standard response algorithms, contributes to a more accurate implementation of their duties by electricians. Such important psychophysiological characteristics as memory and attention during daily training will improve, or remain at the proper level in people of older age groups.

Creating a personalized, with proper prioritization and easy-to-configure digital workplace (with training elements), with easy individual settings, in addition to a disciplining and motivating effect, can also positively affect the emotional state of an employee. We predict a decrease in the level of psychoemotional stress of electricians.

In general, the effect of introducing the «Digital Electrician» concept is:

- reducing the risk of injury;

- increase productivity;

- increasing the transparency of work processes and tasks;

- decrease in the volume of filled out documentation;

- automation of the staff development system.

\section{Conclusions}

Summing up, it is important to note the need for a systematic approach to ensure the reliability of the professional activities of staff. Minimizing the negative impact of the human factor on the risk of injury is possible provided timely diagnosis and regular corrective and preventive work, one of the elements of which is the formation of professionally important qualities of electricians that affect work safety.

\section{References}

1. GOST R 12.1.009-2009. URL: http://cntd.ru/document/1200079431.

2. I.D. Grab, A. V. Zatylkin, V. B. Almametov, N. K. Yurkov, International Papers (KuzSTU, Kemerovo, 2002)

3. P. A. Dolin, Power shock security (MPEI, Moscow, 2012)

4. E. M. Kazina, Asaptation and Health (KRIPKiPRO, Kemerovo, 2009)

5. O. V. Kochin, Emergency Medicine, 8, 78 (2015)

6. B. I. Kudrin, Power regimes (MPEI, Moscow, 2013)

7. Power management safety rules. URL: : http://docs.cntd.ru/document/499037306

8. Power facilities design rules. URL: : http://www.consultant.ru

9. Yu. V. Shcherbatykh, Psikhologiya stressa (Eksmo, Moscow, 2006)

10. ElectronicsWorkbench. MultiSIM. Proektirovanie i modelirovanie (Rossiyskiy filial korporatsii National Instruments, 2006).

11. S. F. Souza, F. M. Carvalho, T. M. Araújo, L. A. Porto, Re. Saude Publica, 44:4 (2004)

12. A. D. Walling, American Family Physician, 54, 8 (2010) 